\title{
PERCEPÇÃO DOS VISITANTES DO PARQỦE ECOLÓGICO “JOÃO DOMINGOS COELHO" EM ASSIS (SP) QUANTO AO MEIO AMBIENTE E AVIFAUNA
}

Stéfani Caroline Queiroz ${ }^{1}$ Fernando Frei ${ }^{2}$

Resumo: O Brasil apresenta uma diversidade rica de aves nativas. Porém, com o desmedido crescimento da zona urbana e avanço dos processos tecnológicos nas últimas décadas, a conservação do ambiente natural e, por consequência, da avifauna estão ameaçados. O presente estudo por sua vez, busca definir o perfil dos visitantes do Parque Buracão, em Assis/SP, quanto ao conhecimento sobre conservação ambiental, a fim de promover 0 desenvolvimento do pensamento conservacionista por meio da observação de aves como ferramenta aliada à educação ambiental. Os resultados exibem a necessidade de projetar atividades que promovam o desenvolvimento da percepção ambiental dos indivíduos.

Palavras-chave: Conservação; Educação Ambiental; Observação de Aves.

${ }^{1}$ Faculdade de Ciências e Letras de Assis. UNESP Assis, E-mail: stefani.queiroz@hotmail.com

${ }^{2}$ Faculdade de Ciências e Letras de Assis. UNESP Assis, E-mail: ffrei@assis.unesp.br

Revbea, São Paulo, V. 13, № 4: 156-173, 2018. 


\section{Introdução}

O Homem sempre se mostrou ambicioso, seja pensando em seu crescimento ou na evolução do meio em que vive. Contudo, com o desenfreado avanço das cidades a partir da segunda metade do século XX, muitos problemas ambientais surgiram, causando impactos negativos na natureza e no próprio ser humano, tanto no Brasil quanto no mundo (MENARIN, 2010).

Reconhecer-se a si mesmo como sujeito da história pode ser complexo, porém este exercício torna-se peça importante na construção do todo (Quadros, 2007: p. 11). Assim, quando o Homem reconheceu os problemas que o Planeta Terra estava sofrendo - e ainda está - por conta principalmente do mau uso dos recursos naturais e produção excessiva de lixo devido ao alto consumismo, conferências mundiais onde se buscava discutir a respeito do Meio Ambiente começaram a serem feitas, como por exemplo, a Conferência de Estocolmo em 1972. Desde então, o pensamento em melhorar a relação Homem-Natureza começou a ser difundido no mundo, buscando trazer possíveis soluções para a degradação ambiental, bem como a tentativa de criar novas tecnologias sustentáveis de avanço econômico e político para as nações.

De acordo com Melazo (2005, p.4-5):

É necessária uma mudança de postura do homem frente às
questões ambientais. A ideia que se tem das cidades como um
espaço de caos, deve ser substituída por uma nova perspectiva
buscando novas formas de administrar os processos sociais
que as produzem e as modificam, ou seja, os procedimentos e
as ações devem compreender as especificidades dos espaços,
suas relações com seus espaços de entorno e sua dinâmica
social, econômica, cultural que neles ocorrem, de maneira
menos predatória possível ao meio ambiente.

Quando falamos a respeito do início das discussões sobre este tema, é importante entender que boa parte dessa problemática surge com a necessidade de diminuir e/ou até tentar reverter grande parte do que já foi impactado no Meio Ambiente, mas também é preciso pensar em como trazer para a população a noção de cuidado e preservação do ambiente.

Ainda que a exploração econômica dos recursos naturais deva associar de modo racional à expansão e as práticas de conservação para proteger a qualidade ambiental, há poucas iniciativas técnicas e éticas para um consenso em propor qual a melhor maneira para encarar os problemas ambientais não percebidos pela sociedade. Provavelmente, os principais motivos são a insuficiência do conhecimento ecológico e do sistema ambiental de interesse, a grandeza e a velocidade das alterações ambientais resultantes das interações humanas associadas ao uso do solo e, especialmente do nível de 
compreensão e percepção da sociedade frente à série de problemas ambientais e as atividades produtoras regionais (FIORI, 2006).

Deste modo, a criação do pensamento conservacionista e a percepção ambiental são extremamente importantes. Apresenta-se neste ponto o termo "conservação" segundo os princípios da IUCN (1984), conforme citado por Fiori (2006):

[...] a gestão da utilização da biosfera pelo homem, de modo a produzir um maior benefício sustentado para as gerações atuais, e manter suas potencialidades para atender às necessidades e às aspirações das gerações futuras.

Portanto, a conservação tem como objetivo tornar o homem membro do processo de proteção do ambiente, fazendo uso dos recursos de maneira racional e criteriosa.

A ideia de conservação da fauna, da flora e do ambiente natural é algo que precisa ser sempre disseminado. Somente assim pode-se haver uma construção do pensamento conservacionista, sejam em escolas, parques, museus de história natural, projetos de educação ambiental entre outros.

\section{Avifauna e sua importância}

A avifauna brasileira possui uma diversidade riquíssima, sendo estimada em torno de 2000 espécies já registradas (CBRO, 2015). Entretanto, com as incessantes intervenções do Homem no ambiente natural, esta diversidade tem sido impactada negativamente. Embora existam espécies de aves que desfrutem da área urbana como, por exemplo, a pomba doméstica (Columba livia) e o bem-te-vi (Pitangus sulphuratus), grande parte sofre com essas modificações (MARINI; GARCIA, 2015, p. 96). O Mutum-do-nordeste (Pauxi mitu), por exemplo, está extinto do ambiente (IUCN, 2017).

Segundo a IUCN (2004), a principal ameaça para as aves brasileiras é a perda e a fragmentação de habitats. A supressão e degeneração do ambiente natural é uma das ameaças centrais, seguida pela captura $(35,5 \%)$. Outras ameaças abrangem a invasão de espécies exóticas e a poluição (14\%), a perturbação antrópica e a morte acidental (9,5\%), alterações na dinâmica das espécies nativas $(6,5 \%$ cada), desastres naturais $(5 \%)$ e perseguição $(1,5 \%)$.

De acordo com Andrade (1997), citado por Lopes (2004, p. 107), sabese da importância que as aves possuem para o ambiente e por isso a conservação é primordial. Sendo um grupo amplamente estudado do ponto de vista conservacionista, as aves são peças essenciais nos ecossistemas, na manutenção do equilíbrio ecológico, como dispersoras de sementes, controle de pragas e até como bioindicadoras de conservação de um determinado ambiente. 
A observação de aves (Educação Ambiental) é caracterizada por ser uma atividade de contemplação, por parte das pessoas, de aves em seu habitat natural. Segundo Andrade (1997), conforme citado por Mélo (2015, p. 26), dedica-se a fotografar e apreciar aves, seja pela sua raridade, beleza, trazendo a quem pratica gratificação pessoal, intelectual, emocional, estética, recreativa e cientifica. Esta atividade é interessante, pois ao passo em que se mostra uma prática saudável para o observador, também pode ser uma fonte de adquirir conhecimento a respeito da natureza e dos animais, bem como uma forma de desenvolver o pensamento conservacionista.

Por serem encantadoras, de fácil contemplação e de canto agradável, as aves se encaixam perfeitamente ao papel de incentivadoras de ações para conservação, servindo como agentes de sensibilização humana em iniciativas práticas de conservação da diversidade biológica em conjunto à sociedade.

Assim, a criação de projetos de educação ambiental em Assis/SP que visem à observação de aves seria uma estratégia para desenvolver o interesse e o conhecimento, e assim a ideia de cuidado com o ambiente seria propagada e feita de forma mais efetiva.

\section{Objetivo}

Dessa forma, o presente estudo busca conhecer qual a percepção dos usuários do Parque Ecológico "João Domingos Coelho", mais conhecido como Parque Buracão, localizado na cidade de Assis, no interior do estado de São Paulo, sobre a presença e a importância das aves para o ambiente e para o Homem, bem como a compreensão a respeito da conservação.

\section{Área de Estudo}

A cidade de Assis está localizada na região sudoeste do Estado de São Paulo e atualmente possui em torno de 103 mil habitantes (IBGE, 2017).

Segundo Brannstrom (2002), o município encontra-se em uma região de tensão ecológica, ou melhor, uma zona de transição entre formações vegetais características da Floresta Estacional Semidecídua e de Cerrado.

O estudo limita-se a área do Parque Ecológico "João Domingos Coelho", mais comumente chamado de Parque Buracão, localizado na cidade de Assis no interior de São Paulo. 


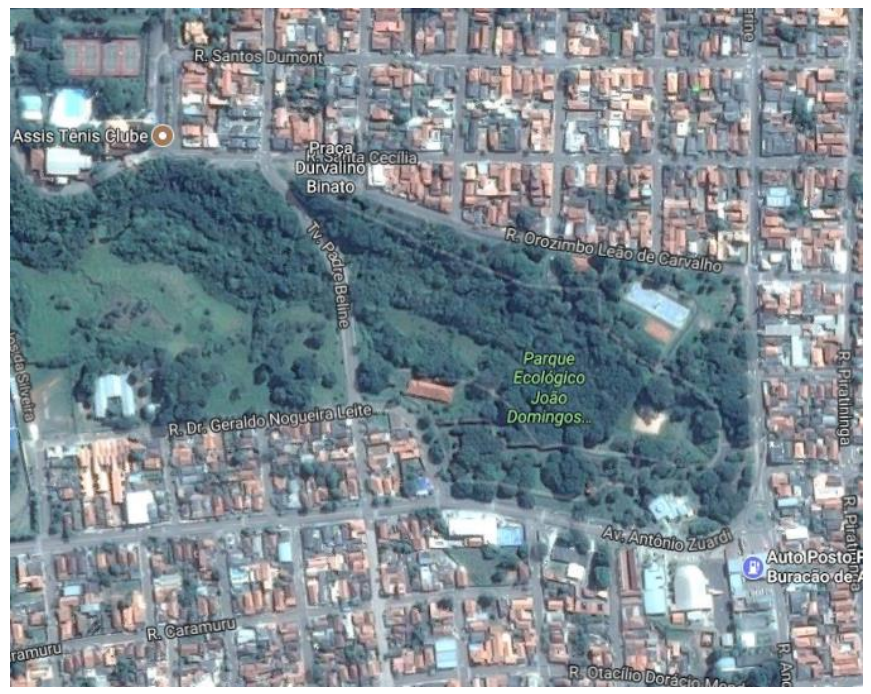

Figura 1: O Parque Buracão. Foto de satélite retirada em <https://maps.google.com.br/>, acessado em: 12 de outubro de 2017.

O local que, antes de ser o atual Parque Buracão, era uma área completamente degradada. Uma enorme cratera havia se formado graças ao avançado processo de erosão em consequência da retirada de grande parte da vegetação em torno do córrego ali presente (NETO, 2006).

Assim, na década de 70 com os inúmeros problemas que o local vinha trazendo para o ambiente e para a população, a Prefeitura Municipal de Assis juntamente com o Governo do Estado de São Paulo, desenvolveu um projeto de recuperação do espaço degenerado (MENARIN, 2010).

Hoje, contamos com um parque arborizado que apresenta duas quadras para prática de esportes, aparelhos de ginástica ao ar livre, trilha para caminhada, orquidário e local para o lazer infantil. Há também o Museu de Arte Primitiva de Assis "José Nazareno Mimessi", inaugurado em 1999, porém o espaço é pouco explorado atualmente. No Parque Buracão, também se encontra a Secretaria Municipal de Agricultura e Meio Ambiente, sendo um órgão importante principalmente no gerenciamento da política de resíduos sólidos urbanos do município.

Pensando em projetos que visem desenvolver os conceitos de cuidado com a natureza envolvendo a comunidade, o Parque Buracão mostra-se como um bom local para a produção desse conhecimento. Visto que é um dos poucos locais de lazer e área verde na zona urbana da cidade, é amplamente utilizado para prática de esportes e passeio por pessoas de todas as idades, além de ser um local habitado por diferentes espécies de aves.

Há presença de diferentes espécies de aves, vistas durante o estudo da área, como a Tesourinha (Tyrannus savana), Pombo-doméstico (Columba livia), Pardal (Passer domesticus), Anu-branco (Guira guira), Sanhaçu-cinzento (Tangara sayaca), Rolinha-cinzenta (Columbina passerina), João-de-barro (Furnarius rufus), Bem-te-vi (Pitangus sulphuratus), Sabiá-Laranjeira (Turdus Revbea, São Paulo, V. 13, № 4: 156-173, 2018. 
rufiventris) entre outros, mostrando-se ser um local com potencial para atividades de observação de aves.

\section{Método}

A pesquisa foi realizada com os visitantes, de forma individual, do Parque Ecológico “João Domingos Coelho" (Parque Buracão) localizado na cidade de Assis/SP, nos dias 21 e 24 de Setembro de 2017 através de um questionário contendo oito perguntas objetivas (Anexo 1).

As questões foram aplicadas no período da manhã (21/09/17) e no final da tarde (24/09/17), sendo os horários onde o parque possui maior fluxo de pessoas. A amostra total é composta por 30 indivíduos, sendo distribuída em 15 mulheres e 15 homens, com faixa etária acima de 18 anos.

Foram utilizados os softwares Microsoft Excel e Instat+ para tabulação e análise dos dados obtidos.

\section{Resultados e discussão}

\section{Perfil dos entrevistados}

Idade

Como parte do questionário, a idade foi um fator a ser analisado. $\mathrm{Na}$ Tabela 1, estabelece-se a idade mínima e máxima dos entrevistados nos dois dias de pesquisa.

Tabela 1: Idade mínima e máxima dos entrevistados.

\begin{tabular}{cc}
\hline Idades & Frequência \\
Idade Mínima & 18 \\
Idade Máxima & 84 \\
Idade Média & 40.333 \\
Número amostral & 30 \\
\hline
\end{tabular}

Fonte: Autoria própria.

A idade mínima estabelecida para a entrevista foi de 18 anos, assim qualquer pessoa com maioridade civil poderia responder. A idade máxima obtida foi 84 anos.

A idade média dos visitantes é de 40 anos, sendo que a maior parte dos indivíduos encontra-se na faixa etária entre 25 a 43 anos (50\%). No estudo de Mello (2015, p.182), maior parte dos entrevistados encontra-se entre 21 e 40 anos de idade, representado por (53,7\%) do total de usuários (Tabela 2 ). 
Tabela 2: Distribuição das idades segundo estudo de Mello (2015).

\section{Idades}

$<20$

Até 30

Até 40

Até 50

Até 60

Até 70

$<70$

Total

\section{Frequência}

5

36

29

16

18

14

3

121

Fonte: Mello (2015).

\section{Sexo}

O gênero dos entrevistados está distribuido de forma que 15 são do sexo masculino (50\%) e 15 do sexo feminino (50\%).

No trabalho de Mello (2015, p. 183), apresenta uma leve diferença, onde os homens representam $49 \%$ e as mulheres, $51 \%$.

\section{Escolaridade}

A Tabela 3 abaixo representa o grau de escolaridade dos indivíduos.

Tabela 3: Grau de escolaridade dos entrevistados.

\begin{tabular}{ccc}
\hline Escolaridade & No de pessoas & $\%$ \\
Analfabeto & 2 & 6,67 \\
Fundamental incompleto & 2 & 6,67 \\
Fundamental completo & 3 & 10,00 \\
Médio incompleto & 1 & 3,33 \\
Médio completo & 8 & 26,67 \\
Superior incompleto & 7 & 23,33 \\
Superior completo & 7 & 23,33 \\
Total & 30 & 100,00 \\
\hline
\end{tabular}

Fonte: Autoria própria.

O grupo mais representado na amostra é dos entrevistados que possuem o nível médio completo, totalizando oito pessoas (26,67\%). Outros grupos de entrevistados encaixam-se nas categorias como superior completo e incompleto, somando sete indivíduos em cada uma respectivamente $(46,66 \%)$.

Mello (2015) encontra estatísticas semelhantes a do presente estudo (Tabela 4). Parte dos usuários do parque encontra-se na categoria médio completo $(52,06 \%)$, seguido por superior completo $(22,31 \%)$. 
Tabela 4: Grau de escolaridade segundo estudo de Mello (2015).

\begin{tabular}{ccc}
\hline Escolaridade & No de pessoas & $\%$ \\
Analfabeto & 0 & 0 \\
Fundamental incompleto & 5 & 4,13 \\
Fundamental completo & 15 & 12,39 \\
Médio incompleto & 1 & 0,82 \\
Médio completo & 63 & 52,06 \\
Superior incompleto & 10 & 8,26 \\
Superior completo & 27 & 22,31 \\
Total & 121 & 100 \\
\hline
\end{tabular}

Fonte: Mello (2015).

\section{Questões sobre o uso do parque}

A Figura 2 apresenta a frequência com que os entrevistados utilizam o parque.

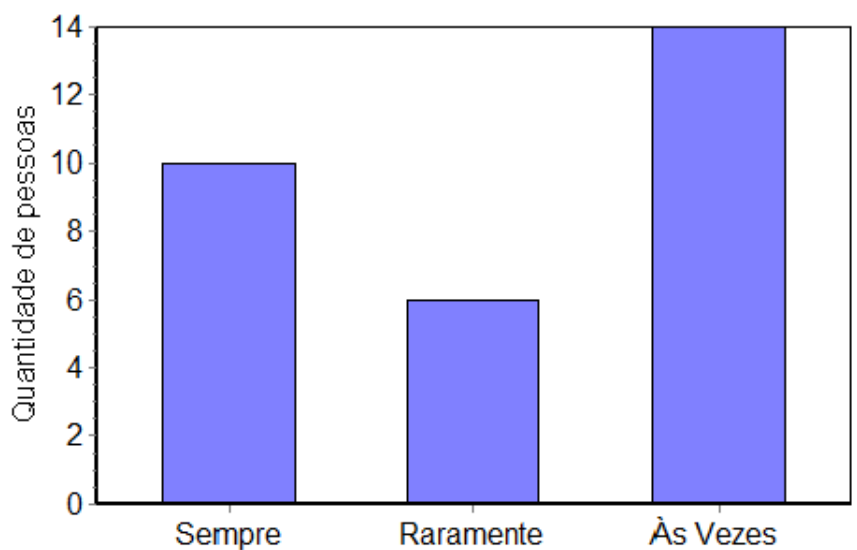

Figura 2: Frequência das visitas feitas pelos entrevistados

Fonte: Autoria própria

Dentre os entrevistados, a maioria costuma visitar o parque às vezes (47\%). Os demais frequentam o parque sempre (33\%) e raramente (20\%). Este aspecto não foi analisado no trabalho de Mello (2015).

Analisando os dados apresentados na Figura 3, nota-se que os homens visitam o parque com maior frequência que as mulheres. 


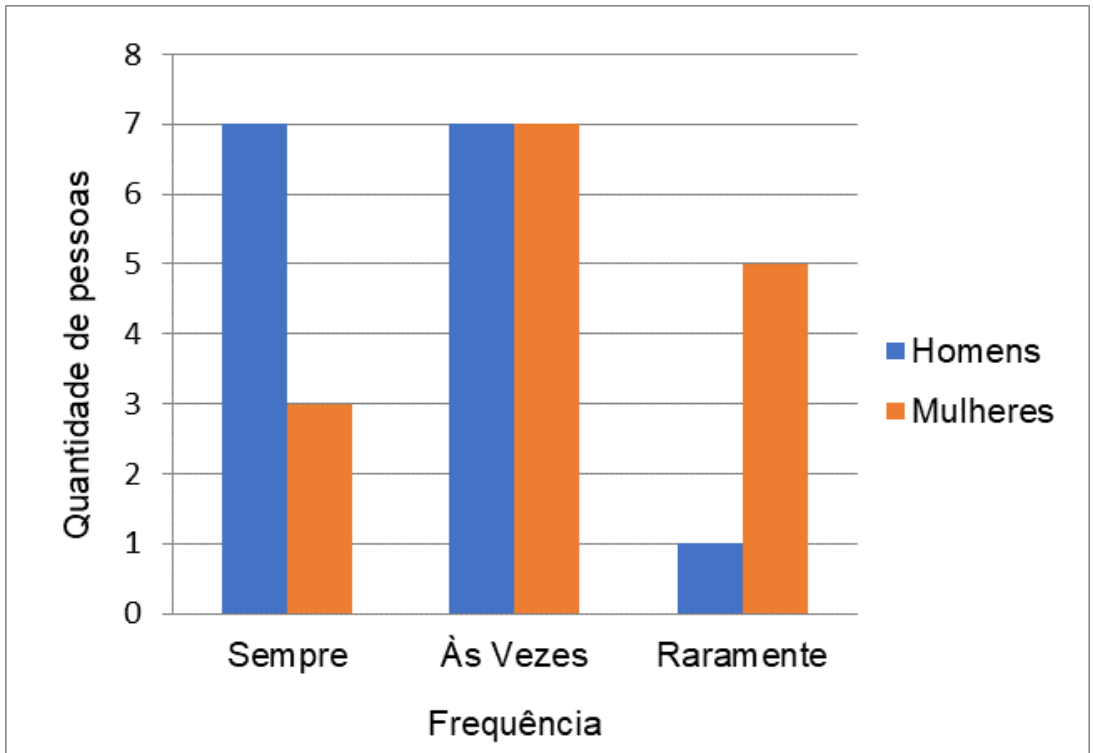

Figura 3: Frequência das visitas divididas por sexo

Fonte: Autoria própria

A Figura 4 exibe o propósito do uso do parque pelos visitantes entrevistados.

A prática de atividades físicas no parque é a principal procura dos entrevistados $(70 \%)$, seja para correr, caminhar, ou utilizar as quadras poliesportivas. Passear (30\%) também é uma das principais ações feitas no parque.

No trabalho de Mello (2015), a prática mais realizada pelos usuários do parque também é a atividade física $(96,6 \%)$, número maior do que encontrado no presente estudo.

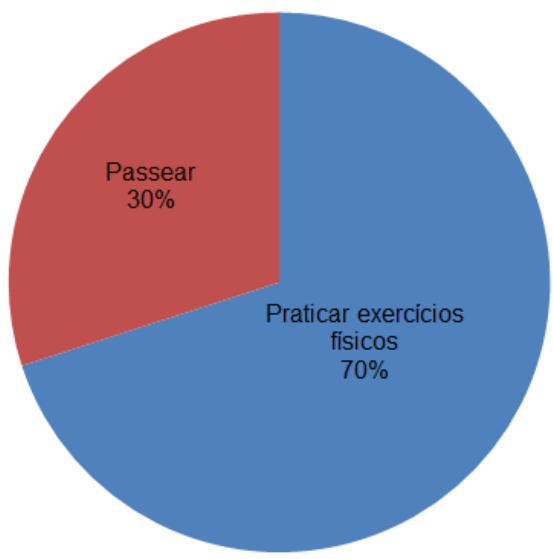

Figura 4: Práticas feitas no parque Fonte: Autoria própria 


\section{Questões sobre a observação de aves e percepção ambiental}

As Figuras 5 e 6 abaixo apresentam o resultado da questão 3: Aqui no parque, você costuma observar as aves?

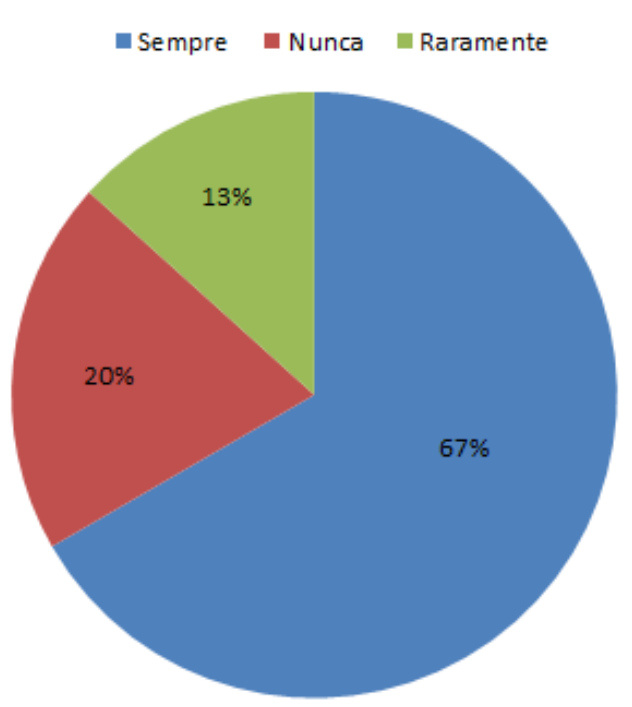

Figura 5: Homens.

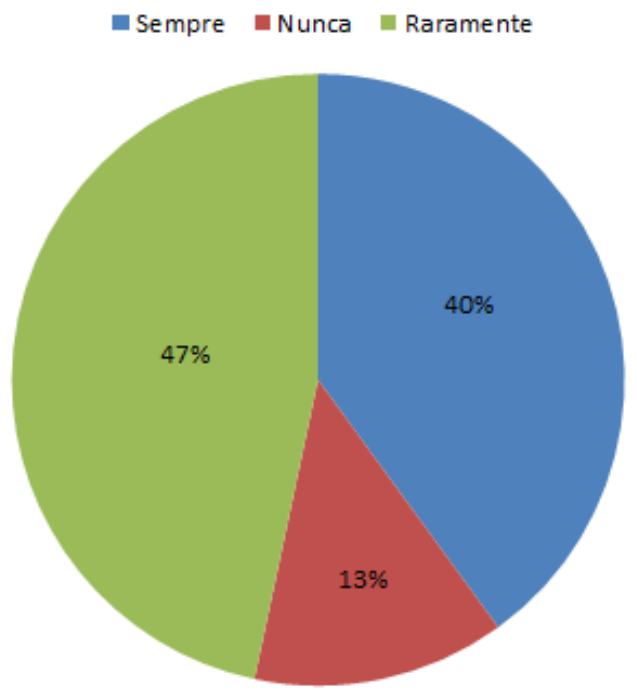

Figura 6: Mulheres.

Fonte: Autoria própria.

Notou-se no estudo de Mello (2015), um número elevado de pessoas que observam a avifauna local no Parque Buracão (74,38\%), enquanto outros apenas ouvem o canto, $25,55 \%$ (ver tabela 6). Semelhante ao trabalho de Mello (2015), no presente estudo também é visto que a observação das aves no parque é feita pela maioria dos entrevistados (figuras 5 e 6). Seja pelo canto ou pela beleza de sua plumagem, a avifauna é bastante apreciada pelo ser humano, atraindo cada vez mais praticantes de sua contemplação em habitat natural (LOPES, 2004).

Dentre os entrevistados, os homens são os que mais observam as aves no Parque Buracão. Alguns alegaram que se sentiam próximos da natureza e mais relaxados ao ouvir o canto dos pássaros enquanto praticam atividades físicas. As mulheres mostraram-se mais distantes da prática de observação, bem como na frequência de visitas ao parque (Figura 3). Conversando com as entrevistadas, muitas disseram não ter tempo para dirigir-se até 0 parque devido ao trabalho e os cuidados com a casa e filhos.

No total, um número razoável de pessoas disse não prestar atenção nas aves (33\%), enquanto outros disseram que raramente observam (60\%). Isso evidencia o grande distanciamento do ser humano com a natureza, provando a necessidade do maior incentivo às práticas de educação ambiental.

Contudo, mudar a concepção dos indivíduos a respeito de um determinado comportamento não é fácil. A escola juntamente com programas 
de educação ambiental, por exemplo, são instrumentos de transformação social que podem contribuir para esta conversão de valores e atitudes. Desse modo, os estudos de percepção ambiental apresentam-se como um instrumento eficaz para melhor compreender as inter-relações entre o homem e o meio, suas expectativas, seus princípios, satisfações e insatisfações, necessidades e comportamento (FIORI, 2007).

Para Espínola (2007), é importante tornar habitual a prática de observação de aves, assim gerando o interesse e a atenção de crianças, jovens e adultos para o tema, garantindo a conservação da diversidade ambiental. Nas escolas, tornando esse interesse relevante no cotidiano dos alunos, a união do grupo das aves com o ensino de ciências e assuntos como sustentabilidade e conservação seria possível.

$\mathrm{Na}$ questão 4 (Tabela 5) sobre identificação das espécies vistas no parque, apenas uma pessoa (3\%) disse saber nomear as espécies que habitam aquele ambiente, seja pelas características físicas do animal ou pelo canto. Os demais, afirmaram saber identificar algumas espécies (50\%), sendo as mais comuns como pombo e bem-te-vi. Um número notável de pessoas declara não saber identificar as espécies observadas (47\%).

Em comparação com o estudo de Mello (2015), os entrevistados declaram saber identificar espécies pelas características físicas $(23,33 \%)$, outros são capazes de dizer nomes populares de aves $(51,11 \%)$. Ver Tabela 6.

Tabela 5: Identificação das espécies vistas no parque

\begin{tabular}{ccc}
\hline Categoria & No de pessoas & $\%$ \\
Sim & 1 & 3 \\
Não & 14 & 47 \\
Algumas espécies & 15 & 50 \\
Total & 30 & 100 \\
\hline
\end{tabular}

Fonte: Autoria própria

Tabela 6: Identificação das espécies segundo estudo de Mello (2015)

\section{Categoria}

Sabe nomes populares

Consegue descrever características

Apenas ouve

Total

$\begin{array}{cc}\text { № de pessoas } & \% \\ 46 & 51,11 \\ 21 & 23,33 \\ 23 & 25,55 \\ 90 & 100\end{array}$

Fonte: Mello (2015)

$\mathrm{Na}$ questão 5, todos os entrevistados responderam que a presença das aves é importante seja no parque, na cidade ou na zona rural. Porém, alguns não souberam dizer qual seria a importância (Tabela 7). 
Tabela 7: Importância das aves

\begin{tabular}{ccc}
\hline Categoria & No de pessoas & $\%$ \\
Importância ecológica & 15 & 33 \\
Preservação do ambiente & 8 & 17 \\
Dispersão de sementes & 6 & 13 \\
Animal de estimação & 0 & 0 \\
Controle de pragas & 4 & 9 \\
Não vejo importância & 0 & 0 \\
Não sei & 2 & 4 \\
Outros & 11 & 24 \\
Total & 46 & 100 \\
\hline
\end{tabular}

Fonte: Autoria própria

$\mathrm{Na}$ questão 6 é perguntado qual seria a importância das aves para o meio ambiente e para os seres humanos, onde os entrevistados poderiam citar mais de uma categoria. Apesar de todos concordarem que a presença da avifauna é importante (questão 5), duas pessoas declaram não saber qual seria. No estudo de Mello, quatro pessoas indicam não saber (2,98\%). Ver Tabela 8.

Tabela 8: Importância das aves segundo estudo de Mello (2015)

\begin{tabular}{ccc}
\hline Categoria & No de pessoas & $\%$ \\
Importância ecológica & 66 & 49,25 \\
Sensações agradáveis & 29 & 21,64 \\
Embelezamento do ambiente & 27 & 20,14 \\
Doenças & 7 & 5,22 \\
Sujeira & 1 & 0,74 \\
Não Sabe & 4 & 2,98 \\
Total & 134 & 100 \\
\hline
\end{tabular}

Fonte: Mello (2015)

Dentre as diferentes atuações em que a avifauna exerce no ambiente, as seguintes foram destacadas para compor o questionário: a importância ecológica, preservação do ambiente, dispersão de sementes e o controle de pragas.

Segundo Laçava (2000) o tráfico internacional de aves e de animais silvestres é uma atividade forte no Brasil, ocorrendo cerca de 12 milhões de animais traficados todos os anos. Deste modo, também foi inclusa outra categoria na qualidade de animal de estimação, um fim infelizmente muito comum para as aves estando intimamente ligada ao tráfico de animais.

A categoria "importância ecológica" foi a mais citada pelos visitantes (33\%). Os indivíduos que apontaram essa esfera, levantaram a atuação das aves na cadeia alimentar e equilíbrio do ambiente como grande relevância para a conservação dos ecossistemas. Comparando com o estudo de Mello (2015, p. 191), $49,25 \%$ dos entrevistados apontam as aves como sujeitos marcantes na importância ecológica, sendo a categoria mais indicada semelhante ao presente estudo (Tabela 8 ). 
A segunda categoria mais referida foi a "outros" (24\%). Nessa categoria encaixam-se todos os entrevistados que veem como importância a ornamentação do ambiente e a alegria do canto que as aves trazem. Nos resultados obtidos por Mello (2015, p. 191), este aspecto também destacou-se, onde estão inseridas nas categorias "embelezamento do ambiente" $(20,14 \%)$ e "sensações agradáveis" (21,64\%) (Tabela 8).

Para Costa (2007), a admiração da beleza presente na avifauna pode auxiliar na educação. O encantamento para com as espécies seja por suas características físicas ou canto, pode ser um estímulo inicial na atividade de observação de aves, sendo capaz de formar a percepção ambiental.

Neste sentido, é válido manter as concepções corretas já existentes, ampliando o conhecimento e sobressaindo do saber simplório.

\section{Conhecimento ornitológico e identificação das espécies}

$\mathrm{Na}$ questão 7, foi perguntado aos entrevistados quais espécies de aves conheciam. Em média, cada visitante citou quatro espécies. O quadro 1 abaixo apresenta as espécies citadas.

Quadro 1: Espécies citadas pelos entrevistados

\begin{tabular}{ccc}
\hline Pombo & Calopsita & Curió \\
Arara & Albatroz & Juruti \\
Seriema & Sabiá & Carcará \\
Pinguim & Tucano & Tuiuiú \\
Quero-Quero & Papagaio & Azulão \\
Pardal & Trinca-Ferro & João-de-barro \\
Maritaca & Anu-Preto & Inhambu \\
Canário & Bem-te-vi & Rolinha \\
Pica-Pau & Coruja & Periquito \\
Coleirinha & Jacutinga & Jandaia \\
Tesourinha & Beija-flor & Saíra \\
Gavião & Louro & \\
Pato & Garça & \\
\hline
\end{tabular}

Fonte: Autoria própria

Pombos, Bem-te-vi e os Pardais são as espécies mais frequentes no meio urbano e do parque, sendo assim as mais citadas. Notou-se um pobre conhecimento ornitológico, alertando assim a necessidade de desenvolver projetos de educação ambiental como, por exemplo, a criação de um grupo de observação de aves no parque. O local possui estrutura para esta atividade, além de haver interesse por parte dos entrevistados (Figura 7).

A prática de observação de aves pode ser feita por pessoas de qualquer idade, para ensino formal ou informal, sem a necessidade do uso de equipamentos exclusivos, nem de um vasto conhecimento ornitológico. Vale ressaltar a existência de um recurso virtual com grande importância entre os 
observadores de aves, o WikiAves (www.wikiaves.com.br). O site engloba a maior comunidade cibernética de observadores de avifauna do Brasil, que na forma de contribuições constroem inventários com fotos, áudios de cantos e informações sobre as espécies brasileiras. O site promove e apoia a prática de observação de aves sendo aberto a todos.

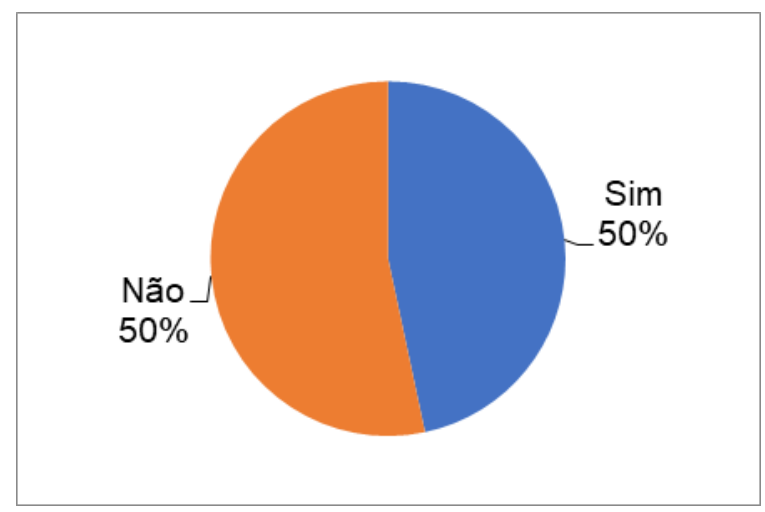

Figura 7: Interesse em aprender sobre avifauna Fonte: Autoria própria

Como foi discutida anteriormente, a concepção do pensamento conservacionista é indispensável para que haja a mudança de visão do ser humano quanto ao ambiente e isso tem que ser conduzido constantemente. Nas escolas a educação ambiental é feita de forma celebrativa e muitas vezes conteudista. Em datas em que são celebrados o Dia da Árvore e o Dia Mundial da Água, por exemplo, são os momentos em que são feitos debates e atividades sobre isso, e em sua maioria, de maneira rasa e nos anos iniciais de ensino. Mesmo assim, não se descarta essa forma de aproximar as crianças à natureza, apenas é enfatizada a grande carência de iniciativas de programas que desenvolvam o interesse a respeito do meio ambiente e avifauna para a população, fugindo desses momentos pontuais.

É interessante salientar que algumas espécies pertencentes aos mesmos gêneros citados pelos entrevistados estão em estado de ameaça.

$\mathrm{Na}$ questão 8 , foi perguntado se os entrevistados apresentavam interesse em aprender sobre as aves. As respostas dividiram-se entre Sim $(50 \%)$ e Não (50\%). Entre os entrevistados do sexo masculino, sete declararam ter interesse em aprender sobre a avifauna, enquanto oito responderam "não". Já entre as mulheres não foi tão diferente o resultado: oito alegam interesse, enquanto sete disseram "não". Este aspecto não foi avaliado no estudo base.

O interesse por parte da população é primordial para que seja possível a aplicabilidade da Educação Ambiental, sendo assim, uma união entre as atividades com a disposição da sociedade (MELLO, 2015).

Comparando os resultados da presente pesquisa com os do estudo base realizado em 2012, é possível notar que não houve grandes transformações na 
percepção dos frequentadores do Parque Buracão perante o meio ambiente e avifauna, indicando a necessidade do desenvolvimento de práticas de educação ambiental no local.

\section{Conclusões}

A realização de estudos ornitológicos com caráter conservacionista tem apresentado um crescimento gradativo, planejando adotar atitudes ativas para conservar a rica e crescentemente ameaçada avifauna brasileira.

O presente estudo, por sua vez, busca conhecer o perfil dos visitantes do Parque Ecológico "João Domingos Coelho", em Assis/SP, quanto ao conhecimento sobre conservação ambiental e de aves a fim de promover o desenvolvimento do pensamento conservacionista por meio da observação de aves como ferramenta aliada à educação ambiental.

A análise dos resultados obtidos exibe a necessidade de projetar atividades que promovam o desenvolvimento da percepção ambiental nos indivíduos, bem como o apreço para com a avifauna presente no local. Portanto, a execução de programas de educação ambiental que dispõe da observação de aves no Parque Buracão, mostra-se uma útil ferramenta. Por serem encantadoras, de fácil contemplação e de canto agradável, as aves se encaixam perfeitamente ao papel de incentivadoras de ações para conservação, servindo como agentes de sensibilização humana em iniciativas práticas de conservação da diversidade biológica em conjunto à sociedade.

Para maior interação dos visitantes para com as práticas de observação de aves, o uso de painéis ilustrativos e educativos sobre as espécies ali presentes no parque, por exemplo, seriam úteis para aguçar o interesse dos indivíduos. Além disso, a presença de monitores capacitados para identificação das espécies, bem como fotografar e gravar cantos é essencial para condução da prática.

Tendo em vista o número de entrevistados, a relação entre a percepção ambiental, o conhecimento sobre aves e o hábito de observação poderia ser avaliada para uma amostra maior, sendo este estudo um suporte para uma pesquisa futura.

\section{Agradecimentos}

À Instituição e seu corpo docente pela oportunidade de fazer o curso e me tornar bióloga. Ao meu orientador Fernando Frei pelo suporte, correções e incentivos. 


\section{Referências}

BRANNSTROM, C. Repensando a Mata Atlântica Brasileira: cobertura vegetal e valor da terra no Oeste Paulista (1900-1930). Vária História, Belo Horizonte, no 26, p. 58-76, 2002.

COSTA, R.G.A. Observação de Aves como Ferramenta didática para Educação Ambiental. Revista Didática Sistêmica, V. 6: p. 33-44, julho a dezembro/2007.

ESPÍNOLA, C.R.R. Aves na escola, análise de livros didáticos do ensino fundamental. Florianópolis, 2007

FIORI, A. A percepção ambiental como instrumento de apoio de programas de educação ambiental da Estação Ecológica de Jataí (Luiz Antônio, SP). 2006. 130 f. Tese (Doutorado em Ecologia e Recursos Naturais) Centro de Ciências Biológicas e da Saúde da Universidade Federal de São Carlos, São Carlos, 2006.

LAÇAVA, U. (coord.). 2000. Tráfico de animais silvestres no Brasil: um diagnóstico preliminar. WWF-Brasil, Brasília.

LOPES, S.F.; ROOSEVELT, J.S. Observação de Aves: do ecoturismo à educação ambiental. Caminhos de Geografia. V. 5, oㅡ 13: p. 103-121, outubro/2004.

MARINI, M.A.; GARCIA, F.I. Conservação de aves no Brasil. Megadiversidade, V. 1, no 1: p. 95-100, julho/2005.

MELAZO, G.C. Percepção Ambiental e Educação Ambiental: Uma Reflexão sobre as relações interpessoais e ambientais no espaço urbano. Olhares \& Trilhas. Uberlândia, V. 6, ํo 6: p. 45-51, 2005.

MELLO, G.F. Percepção dos usuários do Parque Ecológico "João Domingos Coelho" Assis (SP), Quanto ao Meio Ambiente e Aves, Antes e Após a Implantação de Placas Informativas da Avifauna Local. Revista Brasileira de Educação Ambiental (RevBEA), São Paulo, V. 10, № 3: p. 177-199, 2015.

MÉLO, B.P.M. Proposta de observação de aves como atividade estratégica à conservação ambiental no Jardim Botânico Benjamim Maranhão em João Pessoa - PB. 2015. 76 f. Dissertação (Programa Regional de Desenvolvimento e Meio Ambiente - PRODEMA) Universidade Federal da Paraíba, 2015.

MENARIN, C.A. Leituras do Espaço e da Política: Elementos para uma História Ambiental Urbana. II Colóquio da Pós-Graduação em Letras, Assis, p. 267282, 2010.

NEVES NETO, C.C. A Revolução Verde em Assis/SP: História e Meio Ambiente na Agricultura Paulista. In: Pinho, Sheila Zambello de; Saglietti, José Roberto. Pró-Reitoria de Graduação: Núcleos de Ensino. 1 ed. São Paulo: Editora Unesp, 2006, p. 68-76. 
QUADROS, A. Educação Ambiental: iniciativas populares e cidadania. Santa Maria - RS; março/2007.

The IUCN Red List of Threatened Species. Disponível em: <http://www.iucnredlist.org>, acessado em 09 de outubro de 2017.

WikiAves. Disponível em: <http://www.wikiaves.com.br>, acessado em 09 de outubro de 2017.

Comitê Brasileiro de Registros Ornitológicos (CBRO). Disponível em: <http://www.cbro.org.br>, acessado em 12 de outubro de 2017.

Instituto Brasileiro de Geografia e Estatística (IBGE). Disponível em: <https://ww2.ibge.gov.br/home/>, acessado em 12 de outubro de 2017. 


\section{Anexo 1 \\ unesp \\ UNIVERSIDADE ESTADUAL PAULISTA "JÚLIO DE MESQUITA FILHO"}

PERCEPÇÃO DOS VISITANTES DO PARQUE ECOLÓGICO “JOÃO DOMINGOS COELHO" EM ASSIS - SP QUANTO AO MEIO AMBIENTE E AVIFAUNA

\section{Gênero}

Idade

Data

( ) Feminino ( ) Masculino
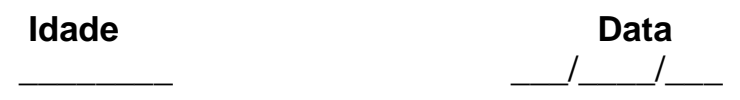

\section{Escolarização}

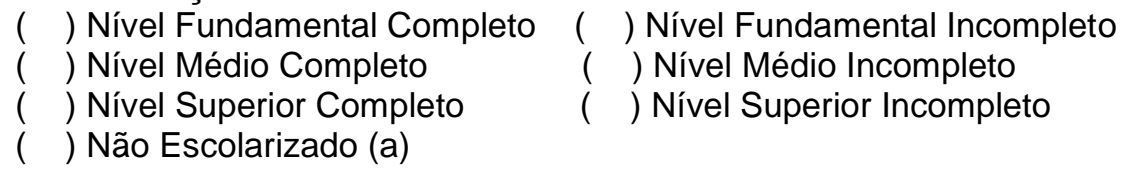

\section{Questões}

1) Com qual frequência você costuma visitar o parque?

() Sempre () Nunca ( ) Raramente () Às Vezes

2) Com qual finalidade?

( ) Praticar exercícios físicos

( ) Passeio

( ) Outros

3) Aqui no parque, você costuma observar as aves?

() Sempre ( ) Nunca ( ) Raramente

4) Se sim, sabe identificar quais são as espécies que está vendo?

( ) Sim ( ) Não ( ) Algumas espécies

5) Você acha importante a presença de aves no parque e na cidade?
( ) Sim
) Não
) Não Sei

6) Para você, qual seria a importância das aves para o meio ambiente e para os seres humanos?

( ) Importância ecológica

( ) Preservação do ambiente

( ) Dispersão de sementes

( ) Animal de estimação

( ) Controle de pragas

( ) Não vejo importância

( ) Não sei

( ) Outros

7) Cite espécies de aves que você conhece.

8) Você tem interesse em aprender sobre as aves?

( ) Sim ( ) Não 